\title{
Strategies for the Individualization of an Informatics Course
}

\author{
Olga Mironova, Irina Amitan, \\ Jelena Vendelin, Merike Saar \\ Faculty of Information Technology, Department of \\ Informatics, Chair of Software Engineering, Tallinn \\ University of Technology, Akadeemia tee St. 15A, Tallinn \\ 12618, Estonia \\ Email: \{olga.mironova, irina.amitan, jelena.vendelin, \\ merike.saar\}@ttu.ee\}
}

\author{
Tiia Rüütmann \\ Faculty of Social Sciences, Department of Industrial \\ Psychology, Estonian Centre for Engineering Pedagogy, \\ Tallinn University of Technology, Akadeemia tee St. 3, \\ Tallinn 12618, Estonia \\ Email: tiia.ruutmann@ttu.ee
}

\begin{abstract}
The present paper describes the strategies used to compile and teach an Informatics course developed during last years at Tallinn University of Technology. The strategy is based on the main principles of blended learning and the analysis of the results of experiments with students from different faculties. Various tests were carried out to identify students' levels of knowledge and preferences in their learning process based on their learning styles. Throughout the experiment, students were divided into groups according to the test outcomes. Separate groups were formed of students with different levels of knowledge and learning styles, determined using the FelderSilverman model.

Adaptive learning tools were provided for the students considering the three main aspects: students' background, the level of their prior knowledge and their preferred learning style. The success of the strategy presented in this article is demonstrated by comparing the achievements of the test group with the reference group, who were not taught using the new strategies.
\end{abstract}

\section{INTRODUCTION}

$\mathrm{E}$ -learning is a rapidly developing world-wide system. Currently, it is not possible to imagine any educational process without e-components or a holistic e-learning system. The main aim of such systems is to provide knowledge in a convenient form for its consumer - the learner. Abundance of information does not guarantee perfect knowledge. Teaching materials should be carefully structured to cater for the needs and preferences of the students.

All present-day knowledge in engineering education is changing so fast that we cannot predict what the 21 th century students will need to know tomorrow. Instead, we should be helping them to develop learning skills and strategies so that they will be able to learn whatever they need to. A combined set of knowledge, skills and attitudes is essential to strengthen productivity, entrepreneurship and excellence in an environment which is based on technologically complex and sustainable products, processes and systems. Similarly, we could improve the quality and nature of engineering education. Thus the objective of engineering education today is to educate students who are ready to engineer, and deeply knowledgeable about technical fundamentals.

Computer science is an integral part of the curriculum, which contents change fast. The general aim of this course is to develop logical, analytical and computational thinking by using the computer on the highest level.

Considering the target audience, several attempts were made to design the course material in the way that it would be easy to understand but would still achieve the goals. Nevertheless, the course seemed to be rather difficult for most of the students. It resulted in low examination grades and lack of motivation.

It became clear that more adaptive learning tools and taking into account individual properties of each student would motivate them and, as a result, would lead to better academic achievements. The question remained how to achieve as much individualization of teaching as possible, using the existing time and personnel resources.

\section{A BRIEF DESCRIPTION OF THE COURSE}

The Informatics course belongs to the curriculum of the Institute of Informatics at Tallinn University of Technology. The aim of the course, designed for the first year non-IT students, is creation of applications by using standard PC equipment and developing object-oriented computational thinking. The learning process starts with processing information using Excel spreadsheets: formulas, diagrams, built-in functions and facilities. The set of practical assignments depends on the students' specialization: economics, social, chemistry and civil engineering.

Further, students learn the basics of programming in practice and the main principles of algorithmization. Python for technical disciplines and Visual Basic for Application (VBA) for humanitarians have been picked out as the programming languages for the second part of this course.

It should be noted that the programming part of the course was complicated for most of the students, especially for the humanitarians. This issue was solved by implementing Scratch in the course curriculum. This intuitive graphical 
programming language helps students to take on board the main ideas such as brunching and cycle.

The Informatics course lasts for two semesters. During this period, we try to combine different styles of teaching and learning: classic face-to-face classroom methods, group work and learning in the Moodle e-environment [9]. The last one gives us a huge amount of different opportunities for individualizing the learning process, such as adjustment of the learning pace, for example, as well as increase and variety in the number of learning assignments. Furthermore, students get a diversity of ways to learn and possibilities for self-tests in the e-part of the course. During the study time, they can choose between different kinds of teaching materials and use what they prefer based on their knowledge and learning styles.

The course is taught in three languages: Estonian, English and Russian.

\section{RESEARCh METHODOLOGY}

\section{A. Overview}

It is generally known that it is not possible to provide all students with one-to-one tutoring at a university. However, this fact should not affect the main educational goal - to ensure high-quality competitive knowledge. In our experiments with course design and curriculum, we considered the differences in students' features, especially their learning styles and prior knowledge.

Since the 2010 fall semester, our group of lecturers has applied a new flexible and adaptive approach to designing computer science e-courses [8]. The basic idea of our methodology is to divide students into equal reference and test groups and to compare the results of these two groups. The reference group is taught using the same course materials and the same e-course but they were not helped with any additional system. The students of the test group, however, were directed in choosing their learning materials based on the data obtained through the tests.

The division into groups was random and was not linked to the students' specialization or knowledge. During the 4 years of the experiment, the group sizes varied depending on the number of students. An average number of participants in the experiment each year was about 100-150 students and they were not aware of the research.

To evaluate the students' progress we tested them at the beginning of the course and at the end of it. The test contents for both groups were similar and were based on the topics described in the European Computer Driving License (ECDL) [1]. The tasks focused on creating documents and presentations, processing spreadsheets, and elementary knowledge in programming.

The last category of the tasks was added recently. In this implementation, we proceeded from an elective course 'Basics of Application Development and Programming', which has been included in the curriculum of Estonian secondary schools.

The current situation of teaching computer science at schools is varied. Some schools do not have computer science lessons at all due to the lack of teachers. Unfortunately, most of those pupils who have obtained sufficient IT-knowledge at their schools are not non-IT students at university level, who our course is aimed at and designed.

\section{B. Research stages}

Theoretically, it is possible to name three main strategies in the process of improving the Informatics course and individualization of the learning process:

$$
\begin{aligned}
& \text { - e-course } \\
& \text { - knowledge } \\
& \text { - learning style. }
\end{aligned}
$$

The first stage, which was named 'e-course', includes the adaptation of the course materials for the e-environment. Theoretical materials and practical assignments were innovated and supported with videos [6] and self-tests. They made the Informatics course more attractive for students. Both groups, the test and the reference group got access to this renewed course. At the same time, face-to-face lessons were held, too. Here we preferred group work that gave the students an opportunity to try the obtained knowledge in practice and develop teamwork skills. In this case the role of the lecturer was slightly different - it became more of an advisor, motivator and supporter in the student's work with learning materials. During the contact lessons learners ask questions related to their homework and share their skills and experience with other. In addition, students have an opportunity to get the support not only from their teacher but from other students, too. This form of support is equally useful both for the students who get it and, especially, for the ones who give it. To find and correct a mistake is an important skill in computer science subjects.

It makes no sense now to enumerate all the advantages of e-learning - they have been known to all. At this stage, we got the first results of our work: positive feedback from students and increase in academic achievements. These results were extracted from the Studies Information System (ÕIS) - an e-environment, where students and teachers get information about courses and curricula, students declare courses, keep results and give anonymous feedback on their educational process [11].

The second stage, titled 'knowledge', is dedicated to the division of the test group students into three streams based on their subject knowledge at the beginning of the course. Those three groups receive different amounts of different level practical tasks in the Moodle e-environment (Fig. 1). So, we increased the number of practical tasks without increasing the subject hours. 


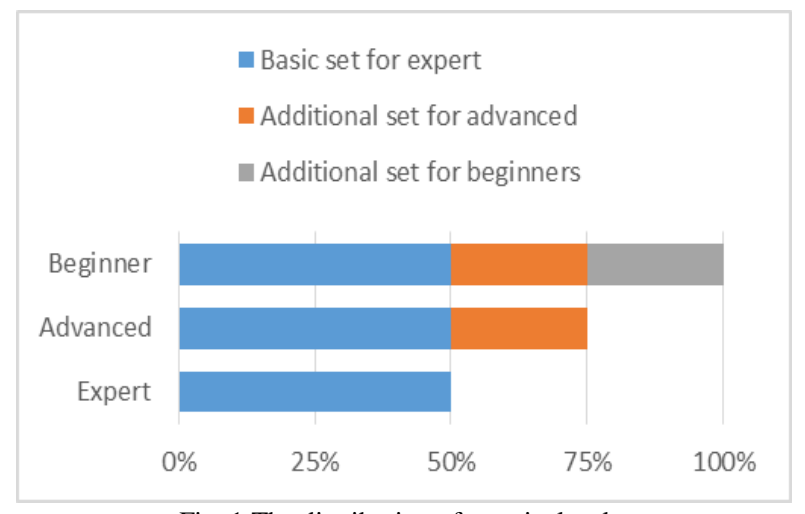

Fig. 1 The distribution of practical tasks

The face-to-face lessons were held as before. The mentioned division provided us with important information about what the students knew before studying our course. Moreover, according to the data we were able to provide them with the necessary learning material.

The success of this stage of experiment was confirmed by positive results of the students' survey in the ÕIS and by the increase in academic results.

The 'learning style' phase of our experiment was the most laborious part. Learning styles are characteristic cognitive, affective, and psychological behaviours that serve as relatively stable indicators of how learners perceive, interact with, and respond to the learning environment. Students learn best when instruction and learning context match their learning style.

There are many studies about the individualization of learning depending on students' ability [7], [3]. Using one of these, the learning styles model of Felder-Silverman, we divided our test group students by their preferences and provided them with corresponding learning materials [3], [4].

Felder distinguishes the following groups of learners depending on their learning styles [2]:

- active and reflective

- sensing and intuitive

- visual and verbal

- sequential and global.

Through this division, we found that the majority of our students were active and visual learners and they had very strong preferences for their learning process. These preferences were detected according to the Felder test which was held at the beginning of the course [10]. Throughout the educational process, students were provided with the necessary learning materials and activities in accordance with Felder's instructions [5]. For example, active learners received more group work and opportunities to help others; visual learners were provided with visual representation of the educational material.

It should be noted that each year the number of active and especially visual students increased (Fig.2).

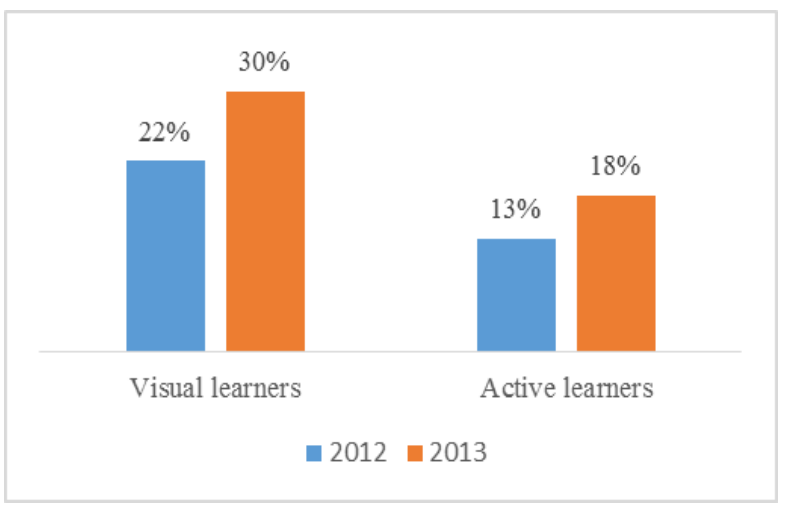

Fig. 2 Increase in the number of visual and active learners

The results of this stage of research showed us that the test group students managed with their practical tasks better than the students of the reference group. This has led to the better academic progress of the test group students.

Thus, we were able to create a model of our students' learning preferences (Fig. 3), which considers their level of knowledge and preferences in the learning process. Using this model, we try to find an individual approach to each student in our course.

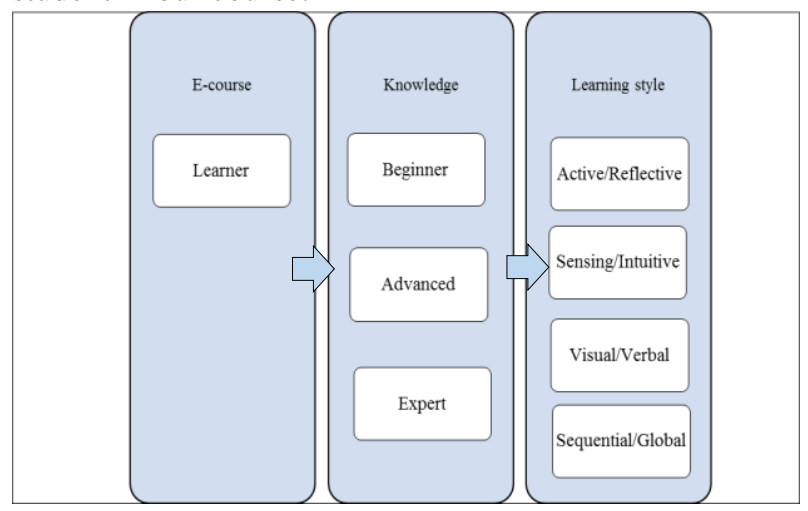

Fig. 3 The model of students' learning preferences

\section{The Method of Research}

Throughout the experiment, positive students feedback and good exam results showed the positive effect of the course and curriculum modifications. Finally, it was decided to examine the data with statistical methods. The aim of this examination is to check and prove the correctness of the chosen approach to an educational process.

As the method of the hypothesis testing, we chose the Student's t-test for the comparison of the two means. This test assumes a normal distribution of samples and not significant differences between the standard deviations of either samples. Our aim is to show that there were no significant differences between the test and reference group students in September, while in January the results are significantly different.

For calculations we use the equations for the averages $\overline{\mathrm{X}}$ (1) and corresponding standard deviation $\mathrm{S}$ for both groups (2): 


$$
\begin{array}{r}
-\bar{x}=\frac{\sum_{i=1}^{n} x_{i}}{n} \\
S=\sqrt{\frac{\sum_{i=1}^{n}\left(\bar{x}-x_{i}\right)^{2}}{n-1}}
\end{array}
$$

After that, we calculated the standard error $\sigma$ using the equation 3 .

$\sigma=\sqrt{\frac{\sum_{\mathrm{i}=1}^{\mathrm{n}}\left(\overline{\mathrm{x}}_{\mathrm{Test}}-\mathrm{x}_{\mathrm{iTest}}\right)^{2}+\sum_{\mathrm{i}=1}^{\mathrm{n}}\left(\overline{\mathrm{x}}_{\mathrm{R} \varepsilon \mathrm{f}}-\mathrm{x}_{\mathrm{iR} \varepsilon \mathrm{f}}\right)^{2}}{\mathrm{n} \cdot(\mathrm{n}-1)}}$

Finally, using equation 4 we calculated the experimental value $t_{\text {exp }}$ :

$$
\mathrm{t}_{\exp }=\frac{\left|\overline{\mathrm{X}}_{\text {Test }}-\overline{\mathrm{X}}_{\text {Ref }}\right|}{\sigma}
$$

In addition, to compare this value with theory we need to calculate the degree of freedom df using equation 5:

$$
\mathrm{df}=2 \mathrm{n}-2
$$

As initial data for calculations, we chose September 2013 students' test results of the test and reference groups, and the same groups' results in January 2014 (cf. Table I in the Appendix).

Both samples are in the equal size: $\mathrm{n}=89$ and distributed normally (Fig. 4 and Fig. 5).

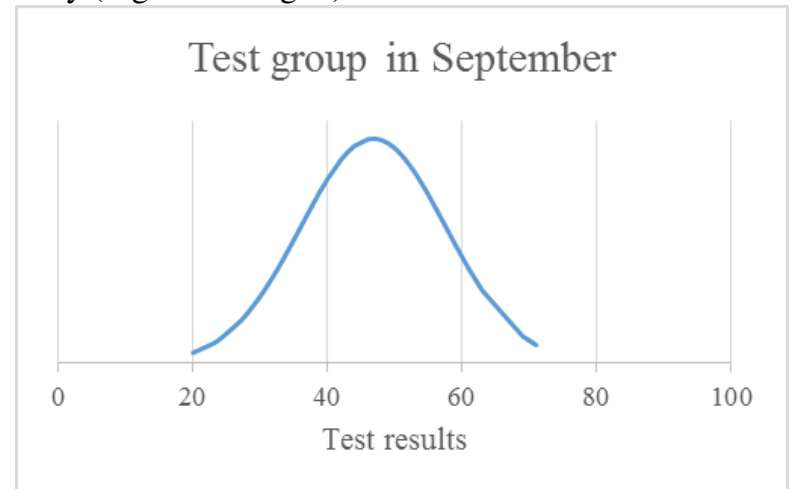

Fig. 4 The distribution of the test group results

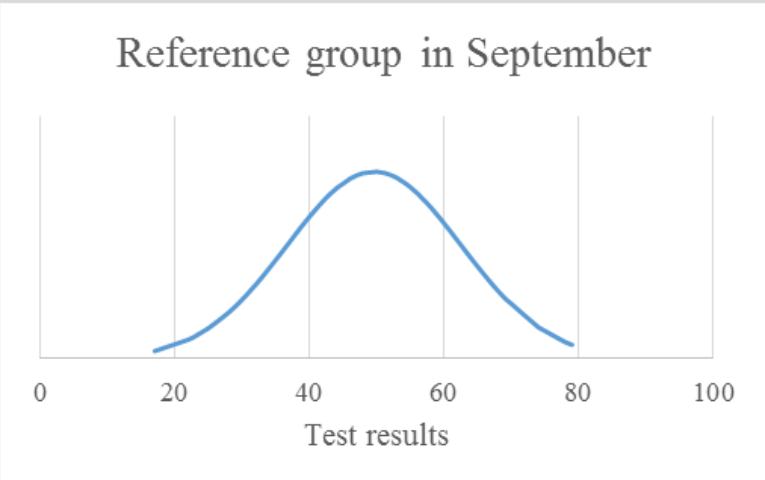

Fig. 5 The distribution of the reference group results
The two means and the corresponding standard deviations are calculated by using the equations 1 and 2 :

$$
\begin{gathered}
\overline{\mathrm{X}}_{\text {Test }}=\frac{4164}{89} \approx 46,787 \\
\overline{\mathrm{X}}_{\text {Rfference }}=\frac{4413}{89} \approx 49,584 \\
\mathrm{~S}_{\text {Test }}=\sqrt{\frac{10222,94}{89-1}} \approx 10,778 \\
\mathrm{~S}_{\text {Rfference }}=\sqrt{\frac{14721,62}{89-1}} \approx 12,934
\end{gathered}
$$

Now we see that there is no significant difference between the standard deviations in either groups. It means that we can continue with Student tests.

The standard error of the difference between the two means is calculated by using equation 3 :

$$
\sigma=\sqrt{\frac{10222,94+14721,62}{89 \cdot(89-1)}} \approx 1,785
$$

Experimental $\mathrm{t}$ value is calculated using equation 4:

$$
\mathrm{t}_{\text {expSept }}=\frac{|46,787-49,584|}{1,785} \approx 1,567
$$

To compare this value with the theoretical $t_{\text {th }}$ we need to calculate the degree of freedom using equation 5 :

$$
\text { df }=2 \cdot 89-2=176
$$

Using equations 1 to 4 we then calculated both groups' results in January 2014:

$$
\begin{gathered}
\overline{\mathrm{x}}_{\text {Test }}=\frac{8029}{89} \approx 90,213 \\
\overline{\mathrm{X}}_{\text {Rfference }}=\frac{6896}{89} \approx 77,443 \\
\mathrm{~S}_{\text {Test }}=\sqrt{\frac{5092,94}{89-1}} \approx 7,608 \\
\mathrm{~S}_{\text {Reference }}=\sqrt{\frac{12518,22}{89-1}} \approx 11,927 \\
\sigma=\sqrt{\frac{5092,94+12518,22}{89 \cdot(89-1)}} \approx 1,499 \\
\mathrm{t}_{\text {exp Jan }}=\frac{|90,213-77,443|}{1,499} \approx 8,489
\end{gathered}
$$

D. Results of the experiment

Using the table of theoretical $t_{\text {th }}$ values with the corresponding degree of freedom (cf. Table II in the Appendix) we found that the means of September results are not different at any critical level:

$$
\begin{aligned}
& \mathrm{t}_{\text {expSept }}<\mathrm{t}_{\text {th }} \\
& 1,567<1,65
\end{aligned}
$$

This means that at the beginning of the course both groups of students, the test and reference, had the same level of knowledge. 
January results are the opposite - the means are different at critical levels.

$$
\begin{aligned}
& \mathrm{t}_{\text {expJan }}>\mathrm{t}_{\text {th }} \\
& 8,489>3,29
\end{aligned}
$$

It shows that the students who were taught using our system of the learning process individualization obtained knowledge much better then the others.

The progress of both groups is shown in the Figure 6 and Figure 7:
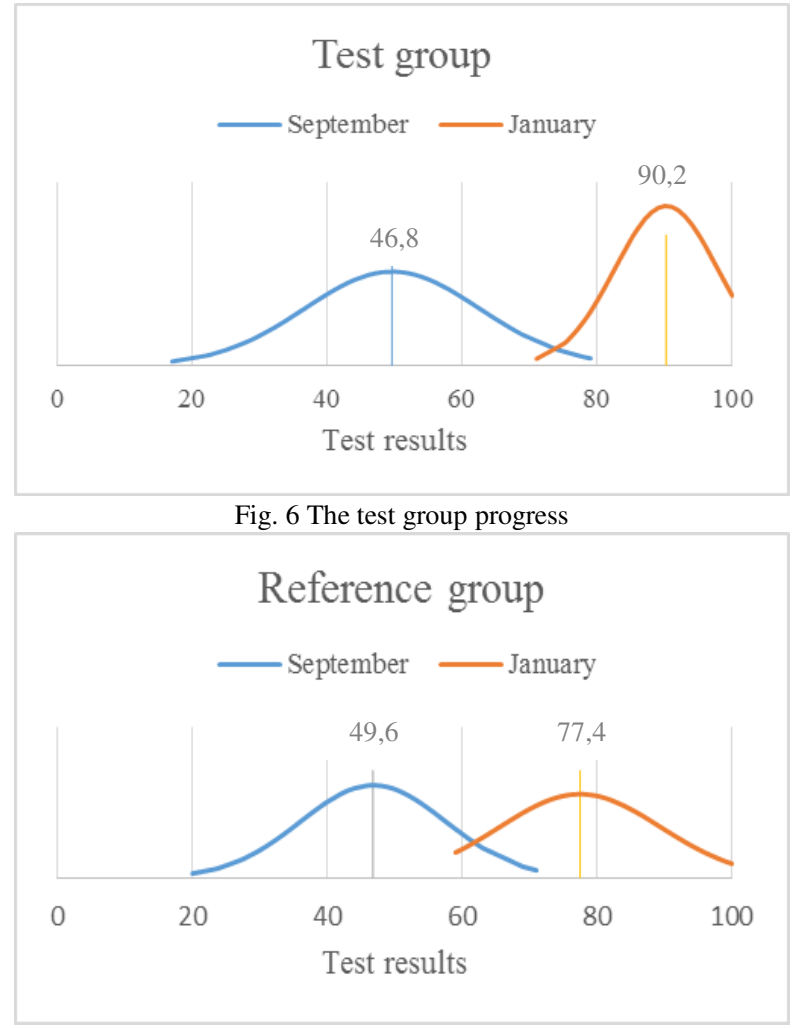

Fig. 7 The reference group progress

These results confirm the validity of our study and the chosen method of course individualization.

\section{CONCLUSIONS}

The analysis presented in the paper shows positive outcomes of the strategy used. The calculations with two relevant groups, the test and reference, demonstrate significant differences in achievements at the end of the first part of the course.

The feedback, received from the groups, is also different. The test group shows higher motivation for further learning compared to the reference group. The main reason for it, picked out by students, was that there were no unreachable targets in the educational process.

Classroom activities of teachers and students took place in mutual communication. Therefore, the guidance and the formative role of the teacher was realized in the creation and review of the theoretical material and the material in practical classes.
The authors intend to continue developing the created model and Informatics course in the same style, trying to adapt it to individual students as much as possible.

\section{APPENDIX}

The results of each group are arranged in two columns under the name of the group in the Table I.

Table II shows only a part of the table of theoretical $t$ values for Student's test. The whole table could be found in any book on statistical analysis. 
TABLE I.

THE TEST RESULTS OF BOTH GROUPS

\begin{tabular}{|c|c|c|c|c|c|c|c|}
\hline \multicolumn{4}{|c|}{ September 2013} & \multicolumn{4}{|c|}{ January 2014} \\
\hline \multicolumn{4}{|c|}{ Groups' results } & \multicolumn{4}{|c|}{ Groups' results } \\
\hline \multicolumn{2}{|c|}{ Test } & \multicolumn{2}{|c|}{ Reference } & \multicolumn{2}{|c|}{ Test } & \multicolumn{2}{|c|}{ Reference } \\
\hline 63 & 52 & 61 & 39 & 89 & 91 & 79 & 72 \\
\hline 52 & 40 & 54 & 59 & 81 & 98 & 84 & 100 \\
\hline 71 & 38 & 78 & 48 & 75 & 91 & 78 & 71 \\
\hline 63 & 40 & 59 & 46 & 91 & 79 & 80 & 62 \\
\hline 53 & 56 & 55 & 40 & 100 & 96 & 77 & 74 \\
\hline 69 & 58 & 58 & 44 & 79 & 98 & 81 & 68 \\
\hline 61 & 48 & 69 & 65 & 71 & 78 & 64 & 60 \\
\hline 69 & 54 & 74 & 57 & 83 & 98 & 60 & 72 \\
\hline 61 & 55 & 60 & 47 & 100 & 100 & 67 & 87 \\
\hline 63 & 40 & 56 & 50 & 89 & 81 & 71 & 86 \\
\hline 61 & 51 & 56 & 64 & 88 & 92 & 84 & 100 \\
\hline 55 & 42 & 61 & 48 & 79 & 98 & 60 & 84 \\
\hline 42 & 39 & 51 & 42 & 89 & 80 & 100 & 78 \\
\hline 59 & 44 & 59 & 46 & 87 & 90 & 79 & 82 \\
\hline 63 & 48 & 53 & 48 & 100 & 90 & 73 & 84 \\
\hline 54 & 55 & 60 & 54 & 89 & 98 & 100 & 92 \\
\hline 48 & 47 & 44 & 46 & 77 & 90 & 66 & 84 \\
\hline 49 & 40 & 55 & 54 & 88 & 93 & 66 & 92 \\
\hline 55 & 32 & 63 & 44 & 85 & 95 & 78 & 82 \\
\hline 44 & 54 & 54 & 17 & 90 & 98 & 96 & 76 \\
\hline 52 & 47 & 61 & 55 & 88 & 86 & 78 & 94 \\
\hline 57 & 44 & 79 & 51 & 100 & 87 & 66 & 60 \\
\hline 55 & 46 & 74 & 50 & 81 & 82 & 72 & 59 \\
\hline 46 & 44 & 53 & 25 & 77 & 91 & 72 & 65 \\
\hline 59 & 34 & 65 & 23 & 90 & 98 & 84 & 63 \\
\hline 55 & 35 & 59 & 30 & 86 & 82 & 78 & 70 \\
\hline 48 & 28 & 36 & 33 & 79 & 98 & 67 & 74 \\
\hline 46 & 40 & 43 & 59 & 87 & 89 & 75 & 100 \\
\hline 53 & 37 & 59 & 55 & 98 & 98 & 91 & 98 \\
\hline 44 & 43 & 55 & 25 & 76 & 96 & 99 & 69 \\
\hline 47 & 43 & 46 & 52 & 90 & 90 & 69 & 96 \\
\hline 52 & 30 & 69 & 34 & 100 & 98 & 62 & 78 \\
\hline 56 & 36 & 68 & 36 & 80 & 94 & 78 & 82 \\
\hline 48 & 44 & 55 & 50 & 92 & 92 & 79 & 96 \\
\hline 44 & 34 & 46 & 41 & 80 & 92 & 70 & 68 \\
\hline 44 & 27 & 47 & 38 & 81 & 100 & 92 & 66 \\
\hline 55 & 42 & 40 & 50 & 98 & 94 & 65 & 100 \\
\hline 51 & 33 & 22 & 46 & 98 & 98 & 76 & 98 \\
\hline 50 & 28 & 67 & 44 & 100 & 92 & 76 & 96 \\
\hline 49 & 40 & 51 & 42 & 86 & 100 & 60 & 66 \\
\hline 35 & 28 & 44 & 23 & 93 & 100 & 73 & 68 \\
\hline 46 & 23 & 57 & 28 & 80 & 94 & 64 & 74 \\
\hline 48 & 20 & 33 & 32 & 86 & 92 & 64 & 72 \\
\hline 48 & 24 & 44 & 42 & 98 & 98 & 76 & 79 \\
\hline 38 & & 38 & & 100 & & 70 & \\
\hline
\end{tabular}

TABLE II.

THEORETICAL $t$ VALUES

\begin{tabular}{|c|c|c|c|c|}
\hline \multirow{2}{*}{$\begin{array}{c}\text { Degrees of } \\
\text { freedom }\end{array}$} & \multicolumn{4}{|c|}{ Probability } \\
\cline { 2 - 5 } & 0,1 & 0,05 & 0,01 & 0,001 \\
\hline$\infty$ & 1,65 & 1,96 & 2,58 & 3,29 \\
\hline
\end{tabular}

\section{ACKNOWLEDGMENT}

The authors thank anonymous FedCSIS 2014 reviewers for their comments and suggestions. In addition, the authors thank the professor emeritus Leo Võhandu, the Senior Research Scientist of Tallinn University of Technology, for his support and contribution to the present research.

\section{REFERENCES}

[1] ECDL Foundation. Retrieved from: http://www.ecdl.com

[2] Felder, R.M. and Brent, R. Understanding Students Differences, Journal of Engineering Education, 2005, 94(1), pp. 57-72. http://dx.doi.org/10.1002/j.2168-9830.2005.tb00829.x

[3] Felder, R.M. and Silverman L.K. Learning and Teaching Styles in Engineering Education, Engr. Education, 1988, 78(7).

[4] Felder, R.M and Soloman, B.A (n. d.) Learning styles and strategies. Retrieved from:

http://www4.ncsu.edu/unity/lockers/users/f/felder/public/ILSdir/styles .htm

[5] Felder, R.M. and Spurlin, J. Applications, Reliability, and Validity of the Index of Learning Styles. Intl. Journal of Engineering Education, 2005, 21(1), pp. 103-112. Retrieved from: http://www4.ncsu.edu/unity/lockers/users/f/felder/public/ILSdir/ILS_ Validation\%28IJEE\%29.pdf

[6] Khan Academy. Retrieved from: http://www.khanacademy.org

[7] Kolb David. "Experiental Learning”, Engle Cliffs, Prentice Hall, 1984, 256 p. Retrieved from: http://academic.regis.edu/ed205/kolb.pdf

[8] Mironova, O., Amitan, I., and Vilipõld, J. Computational Thinking and Flexible Learning: Experience of Tallinn University of Technology. Lecture Notes in Information Technology; 2012, 23-24, pp. 183 - 188. Retrieved from: http://www.ier-institute.org/2070-1918/lnit23/v23/183.pdf

[9] Moodle. Retrieved from: https://moodle.org

[10] Soloman, B. A. and Felder, R.M. (n. d.). Index of Learning Styles Questionnaire. Retrieved from: http://www.engr.ncsu.edu/learningstyles/ilsweb.html

[11] Studies Information System, Tallinn University of Technology. Retrieved from: http://ois.ttu.ee 